48 (1976).

17. Lebenthal, E., Sunshine, P., and Kretchmer, N.: Effect of carbohydrate and corticosteroids on activity of $\alpha$-glucosidases in intestine of the infant rat. J. Clin. Invest., 51: 1244 (1972).

18. Louvard, S., Maroux, J., Baratti, J., and Desnuelle, P.: On the distribution of enterokinase in porcine intestine and on its subcellular localization. Biochim. Biophys. Acta, 309: 127 (1973).

19. Lowry, O. H., Rosebrough. N. J., Farr, A. L., and Randall, R. J.: Protein measurement with the Folin phenol reagent. J. Biol. Chem., 193: 265 (1951).

20. Moog, F.: The functional differentiation of the small intestine. III. The influence of the pituitary-adrenal system on the differentiation of phosphatase in the duodenum of the suckling mouse. J. Exp. Zool., 124: 329 (1953).

21. Moog, F., Birkenmeier, E. H., and Glazier, H. S.: Leucylnaphthylamidase activity in the small intestine of the mouse: Normal development and influence of cortisone and antibiotics. Develop. Biol., 25: 398 (1971).

22. Nordstrom, C., and Dahlquist, A.: The cellular localization of enterokinase. Biochim. Biophys. Acta, 198: 621 (1970).

23. Overton, $J$.: Fine structure of the free surface in developing mouse intestinal mucosa. J. Exp. Zool, 159: 195 (1965).

24. Reel, J. R., and Kenney, F. T.: "Superinduction" of tyrosine transaminase in hepatoma cell culture: Differential inhibition of synthesis and turnover by Actinomycin D. Proc. Nat. Acad. Sci U. S. A., 61: 200 (1968).

25. Rubino, A., Zimbalatti, F., and Auricchio, S.: Intestinal disaccharidase activities in adult and suckling rats. Biochim. Biophys. Acta, 92: 305 (1964).

26. Schimke, R. T., and Doyle, D.: Control of enzyme levels in animal tissues. Ann. Rev. Biochem., 39: 929 (1970)

27. Takano, K., Suzuki, T., and Yasuda, K.: Immunohistochemical localization of enterokinase in the porcine intestine. Okajimas Folin Anat. Jap., 48: 15 (1971).

28. Tomkins, G. M., and Gelehrter, T. D.: The present status of genetic regulation by hormones. In: G. Litwak: Biochemical Actions of Hormones, Vol. II, pp. 1-20 (Academic Press, New York, 1972).

29. I am indebted to Gregory Morrissey, M.S., for his skillful technical assistance, Harry Shwachman for his support and encouragement, and Olga Greengard, the Department of Biological Chemistry at Harvard Medical School, for her criticism, suggestions, and review of the article.

30. This research was supported by the Cystic Fibrosis Foundation, Ina Sue Perlmutter Fund, Illman Foundation, and Hearst Foundation.

31. Requests for reprints should be addressed to: Chief, Division of Gastroenterology, Children's Hospital, 219 Bryant St., Buffalo, N. Y. 14222 (USA)

32. Received for publication June 21,1976

33. Accepted for publication September 22, 1976.
Alternative pathway properdin

$\mathrm{C} 3, \mathrm{C} 3 \mathrm{~b}$ complement

serum

sickle cell disease

inulin

\title{
Alternative Pathway of Complement in Sickle Cell Disease
}

\author{
RONALD G. STRAUSS, (26) THERESA ASBROCK, JUDITH FORRISTAL, AND CLARK D. WEST \\ Department of Pediatrics, The University of Cincinnati College of Medicine and the Comprehensive Center for \\ Sickle Cell Disease, Children's Hospital Medical Center, Cincinnati, Ohio, USA
}

\section{Summary}

Thirty-one patients, 10 months to 20 years of age, were studied. A complement abnormality was not identified in sera from patients with sickle cell disease (SCD) by the methods employed in the present study. Concentrations of C3, factor B, total hemolytic activity (CH50), properdin, and C3b inactivator were similar in sera from patients and control subjects (Table 1 and Fig. 2). Although concentrations of C3b inactivator protein were below normal in a few patients, there was no evidence that these levels were low enough to alter the functions mediated by this protein.

Initiation of the complement sequence via the alternative pathway by reaction with inulin was equal in patient and control sera when assessed by the activation of factor B, cleavage of $\mathbf{C 3}$, and the consumption of hemolytic complement components (Table 1). Lysis of erythrocytes treated with reduced glutathione was similar in patient and control sera during alternative pathway activation (Fig. 3), indicating comparable formation of lytic complexes via this pathway.

An abnormality of the alternative pathway was not detected when the serum from patients with sickle cell disease was reacted with inulin. Thus, this polysaccharide, although commonly employed to assess alternative pathway function, is not satisfactory for studying serum from these patients. In addition, activation of the alternative pathway by cobra venom factor was comparable with controls when assessed by the lysis of glutathione-treated erythrocytes.

\section{Speculation}

Defective function of the alternative pathway of complement activation has been described in the serum of patients with sickle cell anemia. The precise abnormality may be revealed by a quantitative and functional assessment of the components of this pathway.

Fulminant bacterial infections, particularly with Streptococcus pneumoniae, occur with increased frequency in children with SCD $(1,20)$, and several abnormalities of the body defense mechanisms have been reported to account for the propensity to infections in this disorder (7). Defects related to the opsonization, phagocytosis, and killing of bacteria are most important because these defenses are required to control pyogenic infections. An abnormality of pneumococcal opsonization in serum from patients with SCD has been attributed to the heat-labile opsonin system (23). The precise serum defect is as yet unidentified, but evidence suggests that it involves the alternative pathway of complement (8). In this report a quantitative and functional assessment was made of this pathway and related proteins 
in serum from patients with SCD in an attempt to define this abnormality.

\section{MATERIALS AND METHODS}

\section{EXPERIMENTAL SUBJECTS}

Thirty-one patients, 10 months to 20 years of age, were studied. The hemoglobinopathies, as documented by electrophoresis and family studies, were 25 SS, 3 SC, 2 S thalassemia, and $1 \mathrm{SD}$. Results of experiments from the few patients who were not homozygous SS could not be distinguished from the total group, and all data were combined. A total of 59 blood samples were collected, and the patient was judged at the time of venipuncture to be well, infected, or in crisis. Well patients were free of illness for at least 2 weeks. The difficulty in accurately distinguishing infection from crisis is well known, but infection was considered to be present if suggestive symptoms, signs, or chest roentgenograms were accompanied by a temperature higher than $101^{\circ} \mathrm{F}$. It is possible that some of these patients were suffering merely from crisis. The diagnosis of crisis was made when patients were ill, but were afebrile and exhibited no features of infection. Healthy laboratory personnel and 32 normal children (ages 10 months to 19 years) admitted for elective surgery served as control subjects. This study was approved by the committee for human investigation and informed written consent to participate in the study was obtained.

\section{PREPARATION OF SERUM}

Venous blood was clotted at room temperature. The serum was separated within $1 \mathrm{hr}$ by centrifugation, divided into small aliquots, and frozen at $-70^{\circ}$. In most instances each aliquot was thawed once and used in a single experiment.

\section{QUANTITATION OF COMPLEMENT COMPONENTS AND RELATED PROTEINS}

A simplified version of the complement sequence with components of the classic and the alternative pathways is illustrated in Figure 1. Serum concentrations of $\mathrm{C} 3$, factor B and C3b inactivator were determined by radial immunodiffusion in $2 \%$ glycine agarose containing $0.04 \mathrm{M}$ ethylenediaminetetracetic acid (EDTA). Properdin was determined by similar methods using $1 \%$ agarose with $0.04 \mathrm{M}$ EDTA.

The measurement of $C 3$ employed antiserum specific for the $B$ antigenic determinant (22). Antibody was prepared by immunizing goats with $\mathrm{C} 3$ isolated from fresh human serum. Antibodies against other antigens of $\mathrm{C} 3$ were cleared by absorption with

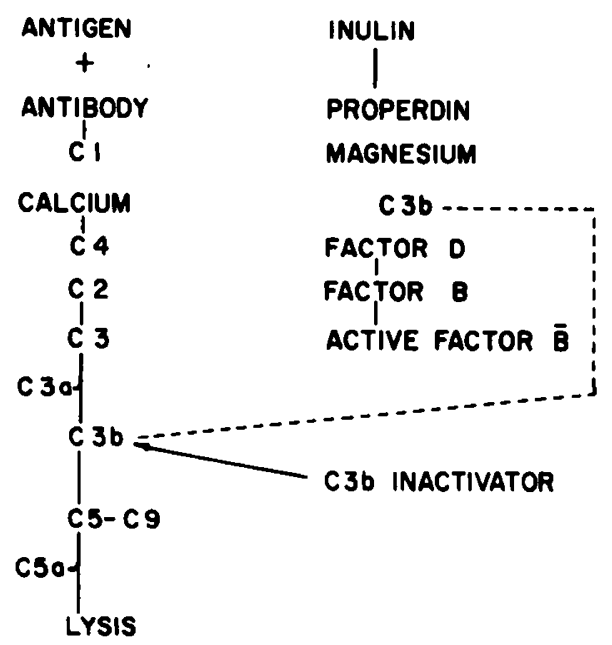

Fig. 1. The components of the classic pathway are listed on the right and the alternative on the left. This simplified diagram is not intended to depict the sequence of reactions accurately. aged serum. The absorbed antibody, when studied by immunoelectrophoresis or by double diffusion, produced a single arc against fresh serum and purified $C 3$ and no arcs with aged serum. The quantity of the $B$ antigen in serum was arbitrarily expressed as $B$ antigen units.

Monospecific antibody to factor B was produced by immunizing goats with purified factor $B$ isolated from human pseudoglobulin (5). The antiserum was absorbed with normal serum previously heated at $56^{\circ}$ for $60 \mathrm{~min}$. This absorbed antiserum, when studied by immunoelectrophoresis and double diffusion, produced a single arc against normal serum and factor $B$.

Monospecific antibody to $\mathrm{C} 3 \mathrm{~b}$ inactivator was produced by immunizing a goat with C3b inactivator (Cordis Laboratories, Miami, Fla.). The antiserum was absorbed with a $\mathrm{C} 3 \mathrm{~b}$ inactivator-free fraction of human pseudoglobulin. This fraction is the protein peak eluted from a BioRex 70 column before factor B, the preparation of which is detailed in the method for isolating factor B (5). The absorbed antiserum, which was studied by immunoelectrophoresis or by double diffusion, produced a single arc when reacted against normal serum and no arcs when reacted against factor $B$ or serum from the patient with $C 3 b$ inactivator deficiency (24). In addition, this antibody was used to absorb normal human serum rendered $0.01 \mathrm{M}$ with respect to EDTA. When the absorbed serum was reconstituted with magnesium, extremely rapid breakdown of $\mathrm{C3}$, assessed by decrease in $B$ antigen concentration, occurred spontaneously. Reconstitution of unabsorbed EDTA serum with magnesium did not lead to $\mathrm{C} 3$ breakdown. Thus, the absorption specifically depleted the serum of the $C 3 b$ inactivator, released its inhibition on the $C 3 b$ feedback loop, and permitted spontaneous cleavage of C3 (16).

Monospecific antibody to properdin was prepared as follows. A goat was injected with crude properdin (18). The antiserum was rendered monospecific for properdin by absorption with human serum depleted of properdin by reaction with zymosan (17). This antibody was then coupled to Sepharose by cyanogen bromide and used to isolate properdin from normal human serum. The same goat was then boosted with the purified properdin, and the antiserum was again absorbed. When studied by immunoelectrophoresis or by double diffusion, the antiserum produced a single arc against normal serum and no arcs against several complement proteins, factor $\mathrm{B}$, and properdin-depleted serum. Total hemolytic complement was measured as CH50 (9).

\section{ACTIVATION OF ALTERNATIVE PATHWAY}

The complement sequence can be initiated via either the classic or alternative pathway (Fig. 1). Inulin selectivity initiates the complement sequence via the alternative pathway, and this polysaccharide is frequently employed to assess the function of this pathway. If the alternative pathway is intact, reaction of serum with inulin will result in activation of factor $B$, cleavage of $C 3$ and consumption of several complement components $(5,14)$. The method used was as follows. Serum was thawed and held in an ice bath. Particulate inulin was added $(10 \mathrm{mg} / \mathrm{ml}$ serum); next, the mixture was vortexed and placed in a shaking water bath for $30 \mathrm{~min}$ at $37^{\circ}$. It was established in preliminary experiments that complement activation was complete within this period. After incubation, the reaction mixtures were cooled in an ice bath, the inulin was removed by centrifugation at $0-4^{\circ}$, and the supernatants were held briefly in an ice bath until studied.

Activation of factor $B$ was assessed by the conversion of the electrophoretic mobility of this protein from $\beta$ to $\gamma(5)$. Immunoelectrophoresis to study factor $B$ mobility was performed in $1.5 \%$ agarose for $25 \mathrm{~min}$ at $40 \mathrm{~V} / \mathrm{cm}$.

Cleavage of $\mathrm{C} 3$ was assessed by the decrease in concentration of the B antigenic determinant that normally accompanies cleavage of this protein (22). C3 is present in fresh serum as $\beta-1-C$ globulin. When serum ages or when the complement system is activated in fresh serum, $C 3$ is converted to $C 3 c(\beta-1-A-g l o b u-$ lin) and C3d ( $\alpha-2-D$-globulin); at this point a portion of the molecule (the $B$ antigenic determinant) can no longer be de- 
tected by immunoelectrophoresis. The extent of reduction of B antigen concentration is a sensitive indicator of $\mathrm{C} 3$ cleavage. Activation of the complement system by inulin with the subsequent consumption of lytic components was assessed by the decrease of $\mathrm{CH} 50$ units.

\section{LYSIS OF GLUTATHIONE-TREATED ERYTHROCYTES}

Human erythrocytes that are treated with reduced glutathione at alkaline $\mathrm{pH}$ are sensitive to complement-mediated lysis and can serve as indicator cells for the generation of lytic complexes via the alternative pathway in a manner similar to erythrocytes from patients with paroxysmal nocturnal hemoglobinuria (6). Human erythrocytes (type $\mathrm{O}, \mathrm{Rh}$ negative) were incubated in $0.2 \mathrm{M}$ reduced glutathione (Boehringer Manheim, New York) at pH 9.0 for $30 \mathrm{~min}$ at $37^{\circ}$. The cells were extensively washed until the supernatant was colorless, suspended in Veronal buffer $(\mathrm{pH}$ 7.4) containing $1.5 \times 10^{-4} \mathrm{M}$ calcium and $1.0 \times 10^{-3} \mathrm{M}$ magnesium, and used within $24 \mathrm{hr}$. These cells were exposed to serum during the activation of the complement system with inulin or cobra venom factor, another substance known to activate the alternative pathway (5). The cobra venom factor was not purified after purchase (Cordis Laboratories, Miami, Fla.), but its anticomplementary activity was assessed by its ability to activate factor $B$ and to cleave $C 3$ in whole serum. The reaction mixtures were incubated at $37^{\circ}$ for $45 \mathrm{~min}$ with inulin and $60 \mathrm{~min}$ with cobra venom factor. Incubation with inulin was shortened because complete lysis occurred within $60 \mathrm{~min}$. The lytic reaction was stopped by adding iced $0.15 \mathrm{M} \mathrm{NaCl}$. The unlysed cells were removed by centrifugation at $4^{\circ}$, the supernatants placed into clean tubes, and the amount of hemolysis determined spectrophotometrically at $541 \mathrm{~nm}$. Three blanks were used with each experiment: (1) complete lysis blank with glutathione-treated cells plus distilled water; (2) color blank containing all components of the reaction mixture except the activating substance (inulin or cobra venom factor); (3) a complete reaction mixture containing serum previously heated at $50^{\circ}$ for $30 \mathrm{~min}$ to assess the requirement for heat-labile serum factors. The optical density of the color blank was subtracted from that of the sample, and the amount of lysis produced by the complement activation was expressed as the percentage of that observed after complete lysis by water.

\section{RESULTS}

Quantitation of complement components and related proteins. Concentrations of $\mathrm{C} 3$, factor $\mathrm{B}$, and total hemolytic activity were similar in serum from patients and control subjects before incubation with inulin (Table 1). As expected, the concentrations of complement components were generally increased in patients who were ill. Concentrations of properdin were measured in sera from five patients and were slightly elevated (Fig. 2). Concentrations of $\mathrm{C} 3 \mathrm{~b}$ inactivator were measured in sera from 17 patients, and the mean value was significantly lower than that of the control subjects (Fig. 2). However, there was considerable overlap into the normal range, and only two values were 2 or more SD below the control mean.

\section{ACTIVATION OF ALTERNATIVE PATHWAY}

Patients and control sera responded almost identically to incubation with inulin (Table 1). Factor B was activated in every serum as indicated by a cathodal shift in electrophoretic mobility to the $\gamma$ region. The fall in $B$ antigen concentrations after reaction with inulin was similar in patients and control subjects, indicating comparable cleavage of $\mathrm{C} 3$. The decrease in $\mathrm{CH} 50$ units was nearly identical, suggesting that the hemolytic complement components were consumed to a similar extent.

\section{LYSIS OF GLUTATHIONE-TREATED ERYTHROCYTES}

Lysis was measured in serum from 10 patients during incubation with inulin and from 17 patients during incubation with cobra venom factor. Lysis was equal to or greater than that of control subjects (Fig. 3). Although the data are not shown in the table, it is important that neither patient nor control serum supported lysis if previously heated to $50^{\circ}$ for $30 \mathrm{~min}$, indicating a requirement for factor $B(5)$, and possibly other heat-labile serum factors. In addition, lysis did not occur in the absence of inulin or cobra venom factor.

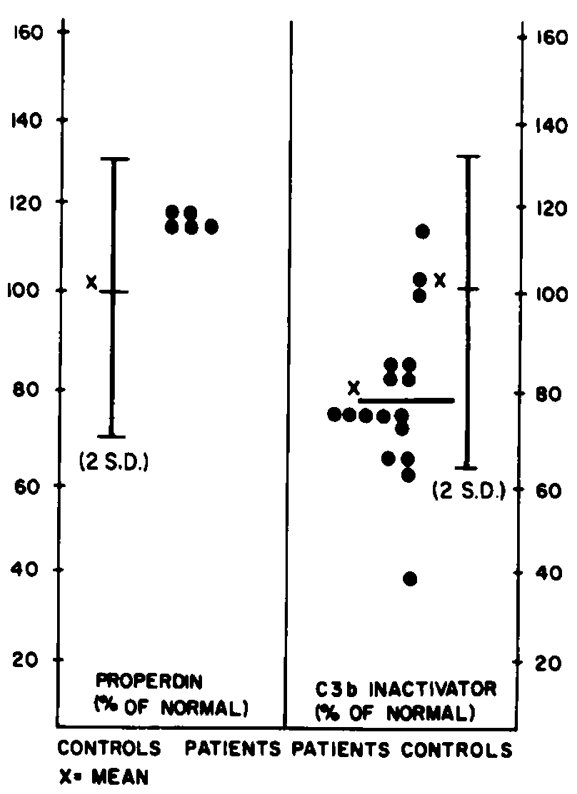

Fig. 2. Concentrations of properdin and $\mathrm{C} 3 \mathrm{~b}$ inactivator in serum. The mean value and 2 SD for $\mathbf{4 5}$ healthy adult control subjects are represented by the bars. The points are individual patient studies.

Table 1. Results of studies performed on 32 samples from 32 normal children and 59 samples from 31 patients

\begin{tabular}{lcccc}
\hline \multicolumn{1}{c}{ Study } & \multicolumn{3}{c}{ Results' } \\
\cline { 2 - 5 } & $\begin{array}{c}\text { Control subjects } \\
(32)\end{array}$ & $\begin{array}{c}\text { Well patients } \\
(26)\end{array}$ & $\begin{array}{c}\text { Infected patients } \\
(22)\end{array}$ & $\begin{array}{c}\text { Crisis patients } \\
(11)\end{array}$ \\
\hline Serum without inulin & & & & \\
C3 (B antigen units) & 33.4 & 29.5 & 28.9 & 34.7 \\
Properdin factor B (mg/dl) & 25.1 & 28.0 & 30.5 & 34.8 \\
$\quad$ Total hemolytic activity (CH50) & 55.6 & 55.7 & 65.5 & $79.6^{2}$ \\
Serum plus inulin & 100 & 100 & 100 & 100 \\
\% sera with shift of factor B from $\beta$ to $\gamma$ & 56.0 & 59.3 & 60.7 & 55.3 \\
\% decrease of original concentration of $\mathrm{C} 3$ & 46.1 & 46.3 & 48.9 & 55.5 \\
\% decrease of original CH50 titer & & & & \\
\hline
\end{tabular}

\footnotetext{
'Mean values.
}

${ }^{2}$ Mean differing significantly from control mean. 


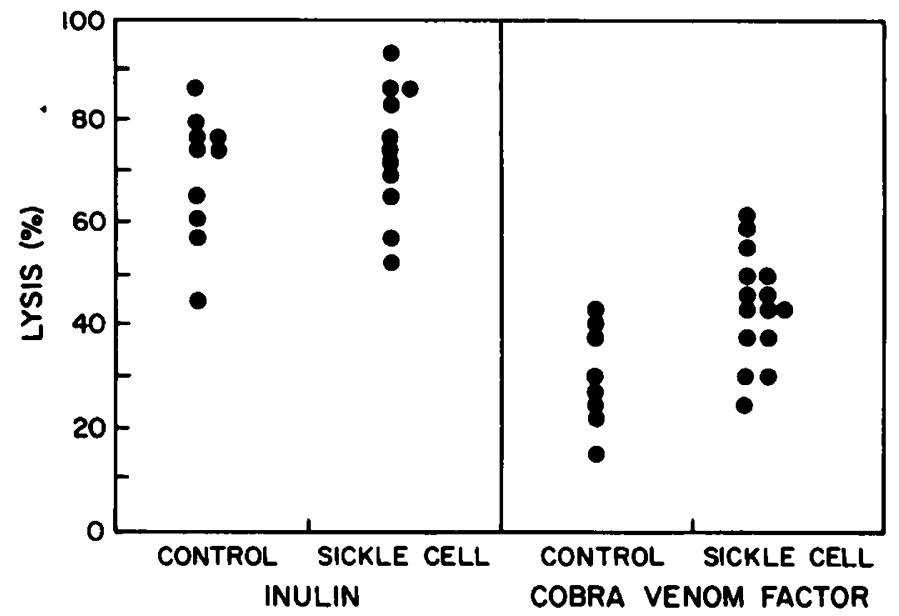

Fig. 3. Lysis of erythrocytes treated with reduced glutathione. The points represent individual studies of control subjects and patients.

\section{DISCUSSION}

It is clear that $S$. pneumoniae are opsonized inefficiently in vitro by the serum of some patients with $\operatorname{SCD}(8,23)$. Winkelstein and Drachman (23) reported such a defect in 12 of 14 patients. They suggested a deficiency of heat-labile opsonins in SCD because: heating normal serum to $56^{\circ}$ for $30 \mathrm{~min}$ destroyed its opsonizing activity and produced an opsonic defect resembling that demonstrated in the patient sera; the pneumococci were opsonized normally when preincubated in fresh normal serum, but not when preincubated in heated normal serum or fresh patient serum; and the concentration of pneumococcal antibodies (heat-stable opsonins) was similar in patients and control subjects. An inhibitor of opsonization was not identified in patient serum.

Johnston and associates (8) confirmed the opsonic defect. Pneumococci were coated with varying amounts of specific antibody and phagocytosis was studied in the presence of fresh serum from patients and control subjects. Antibody alone would not support phagocytosis and fresh serum was required for complete opsonization. Opsonization, as assessed by phagocytosis, was equal in patient and control serum when pneumococci were coated with maximal amounts of antibody. When the amount of antibody was decreased, the mean level of phagocytosis was significantly less in patient serum as compared with control serum. Further studies excluded a relationship of the phagocytic defect to abnormalities of pneumococcal antibodies or the classic complement pathway. An abnormality in the alternative pathway of complement was suggested because zymosan failed to cleave $\mathrm{C} 3$ in patient serum chelated with ethyleneglycol tetraacetic acid (EGTA); i.e., there was no conversion of $\mathrm{C} 3$ into its more anodal form when studied by immunoelectrophoresis, and the zymosan particles were not opsonized with C3. A complement abnormality was not identified in sera from patients with SCD by the methods employed in the present study. Concentrations of $\mathrm{C} 3$, factor $\mathrm{B}$, total hemolytic activity, properdin, and $\mathrm{C} 3 \mathrm{~b}$ inactivator were similar in sera from patients and control subjects. Although concentrations of $\mathrm{C} 3 \mathrm{~b}$ inactivator protein were below normal in a few patients, there was no evidence that these levels were low enough to alter the functions mediated by this protein.

$\mathrm{C} 3 \mathrm{~b}$ inactivator acts as an inhibitor of the $\mathrm{C} 3 \mathrm{~b}$ feedback loop. Continuous activation of the alternative pathway resulting in consumption of factor B and C3 has been demonstrated in a patient with $\mathrm{C} 3 \mathrm{~b}$ inactivator deficiency and hypercatabolism of C3 (24). Apparently, sufficient quantities of C3b inactivator to inhibit the loop were present in patient sera because concentrations of factor B and C3 were not decreased in sera with low concentrations of $\mathrm{C} 3 \mathrm{~b}$ inactivator, nor was there spontaneous cleavage of $C 3$ when these sera were incubated at $37^{\circ}$ for $30 \mathrm{~min}$. Initiation of the complement sequence via the alternative pathway by reaction with inulin was equal in patient and control sera when assessed by the activation of factor B, cleavage of $\mathrm{C} 3$, and the consumption of hemolytic complement components. Lysis of erythrocytes treated with reduced glutathione was similar in patient and control sera during alternative pathway activation, indicating comparable formation of lytic complexes via this pathway.

Our failure to identify an abnormality of alternative pathway function in SCD was unexpected in view of the report of Johnston and associates (8). The design of the two studies is dissimilar, and in some respects they are not comparable.

1 . In the present report, specific complement components and functions were assessed in the sera of patients with sickle cell disease, but the opsonic ability of these sera was not determined. Thus, it is possible, although very unlikely because of the nearly universal finding of an opsonic defect by others $(8,23)$, that the serum of the patients in the present study possessed normal opsonizing ability.

2. Zymosan was used by Johnston et al. (8) to activate the alternative pathway, whereas insulin was selected in the present study for two reasons. The complement system is activated via both the alternative and classic pathways by zymosan $(15,21)$. It has been reported that both pathways participate in the consumption of terminal complement components by inulin (21), however, this substance is thought to initiate the complement sequence only through the alternative pathway (5). This polysaccharide has not been reported to fix $\mathrm{C} 1$, and presumably cannot activate the classic pathway by the usual mechanisms. In addition, the results of the reaction of inulin with serum from SCD patients are of interest because this polysaccharide is employed frequently to assess alternative pathway function.

3. Alternative pathway studies by Johnston and associates (8) were performed using serum chelated with EGTA without added magnesium in an attempt to block the classic pathway. When normal serum is rendered $0.01 \mathrm{M}$ with respect to EGTA, the concentration of ionized calcium decreases from $10^{-3} \mathrm{M}$ to approximately $10^{-12} \mathrm{M}$ and the ionized magnesium from $10^{-3}$ to $10^{-6} \mathrm{M}^{3}$. Although the magnesium concentration decreases by a factor of 1,000 with chelation, it has been demonstrated that such treatment selectively blocks the classic pathway while preserving certain alternative pathway functions (3). In a pilot study, sera from five of our patients with SCD and three control subjects were rendered $0.01 \mathrm{M}$ with respect to EGTA (Sigma Chemical Co., St. Louis) and then reacted with inulin. Complement activation was inhibited by chelation in both patient and control sera. This inhibition was indicated by failure to activate factor B and to cleave C3. This inhibition did not occur when aliquots of these chelated sera were rendered $4 \times 10^{-4} \mathrm{M}$ with respect to magnesium before reacting with inulin (in some experiments magnesium was added to a concentration of $4 \times 10^{-3} \mathrm{M}$ ). The $\mathrm{pH}$ did not fall below 7.2 during chelation, insuring that the calcium remained firmly bound and unavailable for classic pathway activity (19). There was no evidence that the magnesium activated the complement system before the addition of inulin, although this would not be of importance in implicating classic pathway activation since magnesium is known to activate only the alternative pathway (11). Fine and associates (3) emphasized that although their experiments provided quantitative information concerning the concentration of magnesium necessary to support alternative pathway functions, the optimal magnesium concentration would have to be determined separately for other experimental situations. Indeed, other investigators have found it necessary to add magnesium to sera chelated with EGTA to insure optimal alternative pathway function $(2,4,12,19)$. Thus, sera were not chelated with EGTA in this study and comparison of our data with that of Johnston and associates is difficult.

4. The methods for identifying C3 cleavage were different. 
The decrease in B antigen concentration, as used in the present study, is a sensitive indicator that the $\mathrm{C} 3$ molecule has been altered. It is likely that the conformational changes in molecular structure that occur during the conversion of native $\mathrm{C} 3$ into its fragments (13) are detected with more precision by this method than by the studies of electrophoretic mobility and opsonization as employed by Johnston and associates (8).

5 . Diluted serum was studied in the previous reports $(8,23)$, whereas whole serum was studied in the present one. Since undiluted plasma and inflammatory exudates provide the media in which these reactions occur within the body, it may be more analagous to the in vivo situation to study undiluted serum. The concentration of complement components in most exudates is unknown, and there is no proof that this assumption is valid. Winkelstein and Drachman (23) did observe improved opsonization when the concentration of patient serum was increased. Although opsonization was clearly different in patients as compared with control subjects when diluted serum was employed, data were not reported in either study $(8,22)$ to indicate whether a defect would be identified using undiluted serum.

An abnormality of the alternative pathway was not detected when the serum from patients with sickle cell disease was reacted with inulin. Thus, this polysaccharide, although commonly employed to assess alternative pathway function, is not satisfactory for studying serum from these patients. In addition, activation of the alternative pathway by cobra venom factor was also comparable with controls when assessed by the lysis of glutathione-treated erythrocytes.

Activation of the alternative pathway with cobra venom factor was recently reported to be defective in serum from sickle cell patients (10). It was suggested that the mechanism was reduced C3PA convertase (factor D) activity. There is no proven explanation for the different results. However, the hemolytic assays employed were different in the two studies. In addition, the cobra venom factor preparations were not purified further after purchase in either study, and it is possible that nonspecific enzymatic activity was present that could act independently of the cobra venom factor. It is to be emphasized that many substances, including pneumococcal polysaccharide, activate the alternative pathway. Several different mechanisms of activation have been described and each activating substance may require individual study to define the abnormal alternative pathway metabolism in SCD.

\section{CONCLUSION}

Defective opsonization of $S$. pneumoniae in serum from patients with SCD was previously reported to be caused by abnormal alternative pathway function. In the present study, several quantitative and functional studies of the alternative pathway were assessed in serum from children with this disorder in an attempt to define this abnormality. Concentrations of $\mathrm{C} 3$, factor $\mathrm{B}, \mathrm{CH} 50$, properdin, and $\mathrm{C} 3 \mathrm{~b}$ inactivator were similar in serum from patients and control subjects. The alternative pathway was activated by inulin to the same extent in patient and control sera, when assessed by the activation of factor $B$, cleavage of $C 3$, and the consumption of hemolytic complement components. Lysis of erythrocytes treated with reduced glutathione was similar in patient and control sera during activation of the alternative pathway with inulin and cobra venom factor. Thus, differences in the alternative pathway between patients with SCD and normal control subjects were not identified by the methods used in this study.

Note Added in Proof. Two relevant reports appeared after preparation of this manuscript. Grebner and associates (J. Lab. Clin. Med., 89: 153 (1977)) noted that zymosan was poorly opsonized in EGTA serum unless Mg was added. Provisor and associates ((Abstract) Pediat. Res., 10: 380 (1976)) found that $S$. pneumoniae was phagocytized equally well when opsonized with SCD or control sera that had been chelated with EGTA and supplemented with $\mathrm{Mg}$.

\section{REFERENCES AND NOTES}

1. Barrett-Connor, E.: Bacterial infection and sickle cell anemia, an analysis of 250 infections in 166 patients and a review of the literature. Medicine, 50: 97 (1971).

2. DesPrez, R. M., Bryan, C. S., Hawiger, J., and Colley, D. G.: Function of the classical and alternative pathways of human complement in serum treated with ethylene glycol tetraacetic acid and $\mathrm{MgCl}_{2}$-ethylene glycol tetraacetic acid. Infec. Immunology, 11: 1235 (1975).

3. Fine, D. P., Marney, S. R., Jr., Colley, D. G., Sergent, J. S., and DesPrez, R. M.: C3 shunt activation in human serum chelated with EGTA. J. Immunol., 109: 807 (1972).

4. Forsgren, A., and Quie, P. G.: Opsonic activity in human serum chelated with ethylene glycoltetra-acetic acid. Immunology, 26: 1251 (1974).

5. Gotze, $O$., and Muller-Eberhard, $H$. J.: The $C 3$ activator system: An alternate pathway of complement activation. J. Exp. Med., 134: 90 (1971).

6. Gotze, O., and Muller-Eberhard, H. J.: Paroxysmal nocturnal hemoglobinuria; hemolysis initiated by the $\mathrm{C} 3$ activator system. New Engl. J. Med., 286: 180 (1972).

7. Johnston, R. B., Jr.: Increased susceptibility to infection in sickle cell disease; review of its occurrence and possible causes. South. Med. J., 67: 1342 (1974).

8. Johnston, R. B., Jr., Newman, S. L., and Struth, A. G.: An abnormality of the alternate pathway of complement activation in sickle cell disease. New Engl. J. Med., 288: 803 (1973).

9. Kabat, E. A., and Mayer, M. M.: Complement and complement fixation. In: Experimental Immunochemistry, Ed. 2, pp. 133-153 (Charles C Thomas, Publisher, Springfield, Ill., 1961).

10. Koethe, S. M., Casper, J. T., and Rodey, G. E.: Alternative complement pathway activity in sera from patients with sickle cell disease. Clin. Exp. Immunol., 23: 56 (1976).

11. May, J. E., Rosse, W., and Frank, M. M.: Paroxysmal nocturnal hemoglobinuria, alternate-component-pathway-mediated lysis induced by magnesium. New Engl. J. Med., 289: 705 (1973).

12. McLean, R. H., Townsend, M. K., and Michael, A. F.: The effect of anticomplementary substances on properdin in normal and $\mathrm{C} 2$-deficient sera. Clin. Exp. Immunol., 19: 435 (1975).

13. Molenaar, I. L., Helder, A. W., Muller, M. A. C., Goris-Mulder, M., Jonker, L. L., Brouwer, M., and Pondman, K. W.: Physico-chemical and antigenic properties of human C3. Immunochemistry, 12: 359 (1965).

14. Muller-Eberhard, H. J., and Gotze, $\mathrm{O} .: \mathrm{C} 3$ proactivator convertase and its mode of action. J. Exp. Med., 135: 1003 (1972)

15. Nelson, R. A., Jr.: An alternative mechanism for the properdin system. J. Exp. Med., 108: 515 (1958).

16. Nicol, P. A. E., and Lachmann, P.: The alternate pathway of complement activation; the role of $\mathrm{C} 3$ and its inactivator (KAF). Immunology, 24: 259 (1973).

17. Pensky, J., Hinz, C. F., Jr., Toddy, E. W., Wedgewood, R. J., Boyer, J. T., and Lepow, I. H.: Properties of highly purified human properdin. J. Immunol., 100: 142 (1968).

18. Pillimer, L., Blum, L., Lepow, I. H., Wurz, L., and Todd, W. E.: The properdin system in immunity. III. The zymosan assay of properdin. J. Exp. Med., 103: 1 (1956)

19. Platts-Mills, A. T. E., and Ishizaka, K.: Activation of the alternate pathway of human complement by rabbit cells. J. Immunol. 113: 348 (1974).

20. Seeler, R. A., Metzger, W., and Mufson, M. A.: Diplococcus pneumoniae infections in children with sickle cell disease anemia. Amer. J. Dis. Child., 123: 8 (1972).

21. Synderman, R., and Pike, M. C.: Interaction of complex polysaccharides with the complement system; effect of calcium depletion on terminal component consumption. Infect. Immunol., 11: 273 (1975).

22. West, C. D., Davis, M. C., Forristal, J., Herbst, J., and Spitzer, R.: Antigenic determinants of human B1C-and-B1g-globulins. J. Immunol., 96: 650 (1966).

23. Winkelstein, J. A., and Drachman, R. H.: Deficiency of pneumococcal serum opsonizing activity in sickle-cell disease. New Engl. J. Med., 279: 459 (1968).

24. Ziegler, J. B., Alper, C. A., Rosen, F. S., Lachman, P. J., and Sherington, L.: Restoration by purified $\mathrm{C} 3 \mathrm{~b}$ inactivator of complement-mediated function in vivo in a patient with $\mathrm{C} 3 \mathrm{~b}$ inactivator deficiency. J. Cell. Immunol., 55: 668 (1975).

25. This report was presented in part at the combined annual meeting of the American Pediatric Society and the Society for Pediatric Research in April, 1975. The research was supported by Grants HL 15996-01 and AM 13572 from the National Institutes of Health and by ALSAC

26. The present address of $\mathrm{Dr}$. R. G. Strauss is: Division of Hematology-Oncology, Department of Pediatrics, University of lowa Hospitals and Clinics, lowa City, lowa 52242 (USA). To whom requests for reprints should be addressed.

27. Received for publication March 24, 1976.

28. Accepted for publication September 22, 1976. 